\title{
The Effects of Atorvastatin and Methotrexate on Freund's Adjuvant-induced Arthritis in Rats
}

\author{
Rama I. Mahran*, Mohamed M. Ewais, Soha E. Essawy \\ Department of Pharmacology, Faculty of Medicine, Suez Canal University, Egypt
}

\begin{abstract}
Background: Rheumatoid arthritis (RA) is a chronic inflammatory polyarthritis that progressively destroys synovial joints. Statins have been shown to have anti-inflammatory and/or immunomodulatory activities, many studies have focused on the ability of statins to modulate chronic inflammatory diseases, such as RA. Methotrexate (MTX) has become the leading disease modifying antirheumatic drugs (DMARD) for the treatment of RA and other autoimmune diseases. Aim: to determine the anti-inflammatory effect of atorvastatin in combination with MTX on the course of experimentally -induced arthritis in rats. Materials and Methods: rats were divided into 6 groups(Control, arthritic control, atorvastatin, MTX, combination of both in full and half doses) for 28 days. Afterwards they were sacrificed and serum level of TNF- $\alpha$ was determined together with the histopathology for the joints of each group. Results: The oral administration of atorvastatin (5-10mg $/ \mathrm{kg} /$ day) and MTX (0.3-0.5 $\mathrm{mg} / \mathrm{kg} /$ day) in rats that were previously injected with CFA (either as a monotherapy with atorvastatin or MTX or as a combination of both in full or half doses for 28 days) significantly lowered TNF- $\alpha$ levels in sera. They also significantly reduced the histopathological changes compared with the arthritic control group. The best results were for the combination treatment especially with the full dose regimen. Conclusion: Statins possess a useful anti inflammatory effect in patients of RA especially when combined with other DMARDs.
\end{abstract}

Keywords: tumor necrosis factor-alpha, statins

\section{Introduction}

RA is a chronic inflammatory disorder, characterized by joint inflammation with concomitant destruction of cartilage and bone $^{(1)}$. The pro-inflammatory cytokines; tumor necrosis factor-alpha (TNF- $\alpha$ ), interleukin-1 (IL-1) and IL-6 are shown to play an important role in the pathophysiology of arthritis development in animal models and in human ${ }^{(2)}$. Statins represent a class of drugs that are widely prescribed for the treatment of hypercholesterolemia ${ }^{(3)}$. Statins influence multiple steps in the inflamm- atory process, including leukocyte migration and adhesion, T-cell stimulation, nitric oxide (NO) bioavailability, generation

of free radicals, and angiogenesis ${ }^{(4)}$. Atorvastatin activates nuclear receptor $\mathrm{Pe}$ roxisome proliferator-activated receptor gamma (PPAR- $\gamma$ ) in primary human monocytes in culture, in turn decreasing TNF- $\alpha$ production $^{(5)}$. MTX has become the leading DMARD for the treatment of RA in much smaller doses than those used in the treatment of neoplasia ${ }^{(6)}$. Apart from the interference with folate biosynthesis, MTX was found to influence adenosine level and 
interact with adenosine receptors on immune-effector leucocytes ${ }^{(7)}$ The use of MTX has been limited by some of its toxic manifestations ${ }^{(8)}$. The use of combination therapy of MTX or other DMARDs for RA has been suggested to improve efficacy and minimize toxic side effects via decreasing the dose of individual agents ${ }^{(8)}$.

\section{Materials and Methods}

\section{Animals}

A total of 36 adult male albino Wistar rats, weighting 200-250 gm each, were used in this study. Animals were purchased from the national centre of research, Cairo, Egypt. Animals were housed in polyethylene cages at room temperature (under controlled environmental conditions) and were kept with free access to standard rodent chow diet and tap water ad libitum. Animals were allowed for acclimatization for one week before the start of the study.

\section{Materials}

Atorvastatin was purchased from Amoun Pharmaceutical Company, Cairo, Egypt as a white powder dissolved in distilled water. MTX was purchased from T3A Pharmaceutical Company, Cairo, Egypt as yellow powder dissolved in distilled water. CFA was purchased from Sigma biosciences, Egypt as a ten $\mathrm{ml}$ amber viscous liquid containing light-colored particulates. Each milliliter contains $1 \mathrm{mg}$ mycobacterium tuberculosis; heat killed and dried $0.85 \mathrm{ml}$ mineral oil and $0.15 \mathrm{ml}$ mannide monooleate, stored at 2$8^{\circ} \mathrm{C}$ and shaken well before use. Rat TNF- a enzyme linked immunosorbent assay (ELISA) kits were purchased from Biosource Company, Camarillo, CA, USA.

\section{Experimental groups}

Animals were randomly allocated into six groups ( 6 animals each); they received the drugs by oral gavage in a volume of $2 \mathrm{ml} / \mathrm{kg}$ for 28 days. Group 1 (Normal control): nonarthritic that received distilled water (the drug vehicle) once daily. Group 2 (Arthritic control): injected intradermally in the plantar surface of the right hind paw with $0.1 \mathrm{ml}$ of CFA to induce arthritis and left for 10 days until the first signs of joint inflammation were noted. They received the drug vehicle once daily. Group 3 (Atorvastatin group): Arthritic group treated with atorvastatin $10 \mathrm{mg} / \mathrm{kg}$ once daily ${ }^{(9)}$. Group 4 (Methotrexate group): Arthritic group treated with methotrexate $0.5 \mathrm{mg} / \mathrm{kg}$ twice a week $^{(10)}$. Group 5 (Atorvastatin plus Methotrexate group, full dose): Arthritic group treated with atorvastatin $10 \mathrm{mg} / \mathrm{kg}$ plus methotrexate $0.5 \mathrm{mg} / \mathrm{kg}$. Group 6 (Atorvastatin plus Methotrexate group, half dose): Arthritic group treated with atorvastatin $5 \mathrm{mg} / \mathrm{kg}$ plus methotrexate $0.3 \mathrm{mg} / \mathrm{kg}$._After 28 days, blood samples were collected from retro-orbital plexus of each rat before sacrificing them, via a microhematocrite capillary tube inserted at the inner canthus of the eye, $5 \mathrm{ml}$ of blood was collected from each rat in a clean sterile test tube, centrifuged at $2000 \times \mathrm{g}$ for 15 min after $30 \mathrm{~min}$ of collection Then, serum samples were withdrawn and stored at $-80^{\circ} \mathrm{C}$ until cytokine estimation.

\section{TNF- $\alpha$ measurement}

Serum levels of TNF- $\alpha$ were measured by ELISA (Enzyme-linked immunosorbent assay) using the rat TNF- $\alpha$ kits according to manufacturer's instructions.

Histopathological examination:

After scarifying the animals by decapitation, each rat was fixed in a dissector plate, the right hind paw joint was cut about 0.5 $\mathrm{cm}$ above and below the joint. All the skin and muscles were trimmed away so that the joint was left with intact synovial membrane. The joint were decalcified by immersion in $3 \%$ nitric acid solution and main- 
tained at room temperature for an average of 5-7 days. The acid solution was changed every 24 hours; decalcification was monitored by gently feeling the consistency of the bone by the tips of the fingers until it becomes firm to soft. Then it was fixed in $10 \%$ neutral buffered formalin for 2 days. The decalcified specimens were submitted to histologic processing which comprised sequential immersions in alcohol, xylne, liquid paraffin and lastly embedded in paraffin $^{(11)}$. Serial sections were cut (3-4 mm thick), to be subjected to staining with hematoxylin and eosin (H\&E) and examined microscopically for the presence of arthritis (concerning inflammation). Joints were graded using a modified version of a previously adoped system ${ }^{(12)}$. Cell infiltration in the synovial fluid was graded from 0 to 3 as follows: $0(n o)=$ no inflammatory cells in the joint cavity, 1 (mild)= a few inflammatory cells in the joint cavity, 2 (moderate)= joint cavity partly filled with inflammatory calls, 3 (marked)= joint cavity totally filled with inflammatory calls. Destruction of the cartilage was graded as follows: o (no)= normal appearance, 1 (mild) $=$ minor signs of destruction, 2 (moderate) = up to $30 \%$ of destruction, 3 (marked) = more than 30\% of destruction. Scoring was carried out by a blinded pathologist for the experimental groups.

\section{Statistical analysis}

All data were expressed as mean \pm SEM. and analyzed using the Statistical Package of Social Sciences (SPSS) program version 17, (Chicago, IL, USA). All the comparisons among groups were carried out using oneway analysis of variance (ANOVA) followed by post-hoc Bonferroni test to assess the significance of the difference of mean values among groups. A value of $p<0.05$ was considered to be statistically significant.

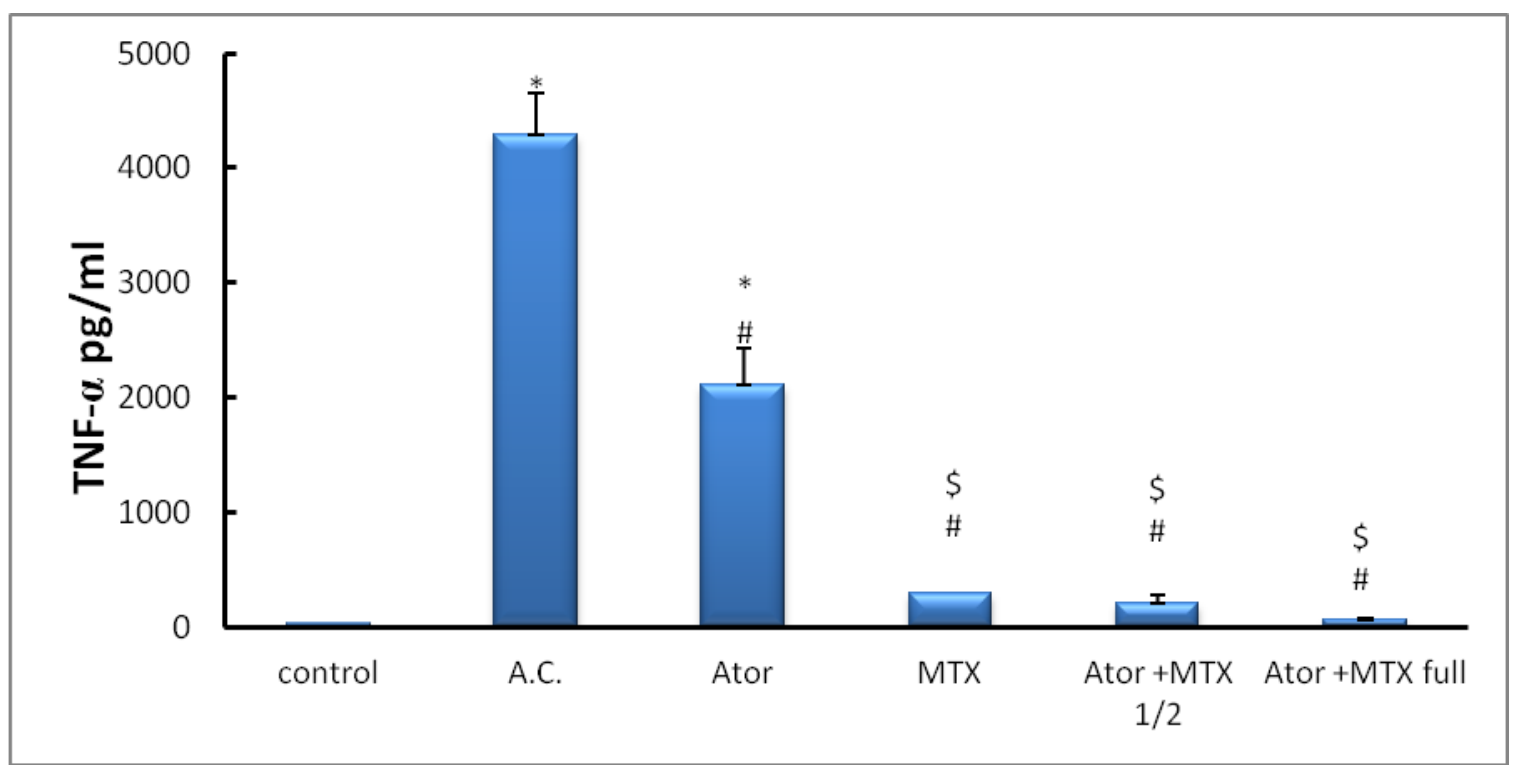

Figure 1: Serum TNF-a level in the experimental groups. Monotherapy with methotrexate or its combination with atorvastatin in both doses significantly ameliorated serum TNF- $a$ level as compared to arthritic controls and atorvastatin treated groups. AC: arthritic control, Ator: atorvastatin, MTX: methotrexate. Results were expressed as mean \pm SEM and analyzed using one-way ANOVA followed by Bonferroni's test. ${ }^{*} P<0.05$ vs. control group, ${ }^{\#} P<0.05$ vs. AC group, ${ }^{\$} P<0.05$ vs. atorvastatin group, $n=6$. 


\section{Results}

Serum TNF- $\alpha$ level in groups under investigation

The results of the present study showed that CFA-induced arthritis in rats resulted in a significant increase in TNF- $a$ serum level as compared to control rats $(p<0.05)$. Oral monotherapy with atorvastatin $10 \mathrm{mg} / \mathrm{kg} / \mathrm{d}$ or MTX $0.5 \mathrm{mg} / \mathrm{kg}$ twice a week for 28 days as well as combination of both in full or half doses resulted in a significant improvement of TNF-a serum level compared to arthritic control group best for full dose $(P<0.05$, Fig. 1).

Histopathological changes:

Normal control group showed normal articular surface without edema and normal ligamentous parts as well as no inflammatory infiltration and no cartilage erosion was observed (Fig. 2). Joint sections in adjuvant arthritic control group showed marked thickening of the fibrous ligamentous parts, marked thickening of articular cartilage, marked lymphoplasmacytic inflammatory infiltrate and moderate neutrophilic infiltration about 50\% associated with moderate degree of Fibrosis and mild cartilage destruction (Fig. 3). Atorvastatin monotherapy showed mild inflammatory infiltrate, moderate fibrosis, marked cartilaginous plate thickening, mild neutrophilic infiltration $5 \%$ and mild destruction of cartilage (Fig. 4). MTX monotherapy showed mild inflammation, moderate fibrosis, marked cartilaginous plate thickening and mild neutrophil infiltration $5 \%$ mild cartilage destruction (Fig. 5). Joint sections of combination (full dose) group showed Moderate inflammation, mild degree of fibrosis and neutrophil infiltration 20\% (Fig.6) and no cartilage destruction. Those treated with both drugs (half dose) group showed moderate inflammation, mild degree of fibrosis, mild cartilaginous hyperplasia and neutrophil infiltration $10 \%$ and no cartilage destruction (Fig. 7). The mean percent of neutrophil infiltration in the arthritic control group was $50 \% \pm 1.87$. Monotherapy with atorvastatin/MTX or their combination in the above mentioned doses resulted in a significant decrease in the percent of neutrophil infiltration as compared to arthritic control group $(\mathrm{P}<0.05)$. The combination treatment in either full or half doses resulted in a significant increase in neutrophil influx as compared to monotherapy with MTX or with atorvastatin ( $P<0.05$, Fig. 8). The mean percent of neutrophil infiltration in the arthritic control group was 50\% \pm 1.87. Monotherapy or their combination in the above mentioned doses resulted in a significant decrease in the percent of neutrophil infiltration as compared to arthritic control group $(\mathrm{P}<0.05)$. The combination treatment in either full or half doses resulted in a significant increase in neutrophil influx as compared to monotherapy with methotrexate or with atorvastatin $(P<0.05$, Fig. 8). The mean score of cartilage destruction was $2.8 \pm 0.11$ in the arthritic control group. Monotherapy with atorvastatin did not significantly decrease the cartilaginous plate thickening score whereas monotherapy with MTX as well as its combination with atorvastatin in half or full dose resulted in a significant decrease in the cartilage destruction score compared to arthritic control and atorvastatin groups. In addition, combination therapy in full doses significantly ameliorated this score as compared to monotherapy with methotrexate ( $p<0.05$, Fig. 9).

\section{Discussion}

RA is a chronic inflammatory polyarthritis that progressively destroys synovial joints. There is no known cure and, despite improved therapy, the long-term prognosis remains poor, with a reduced average life expectancy ${ }^{(13)}$. Growing evidence suggests 
that early treatment of RA with a combination of DMARDs may induce long-term and

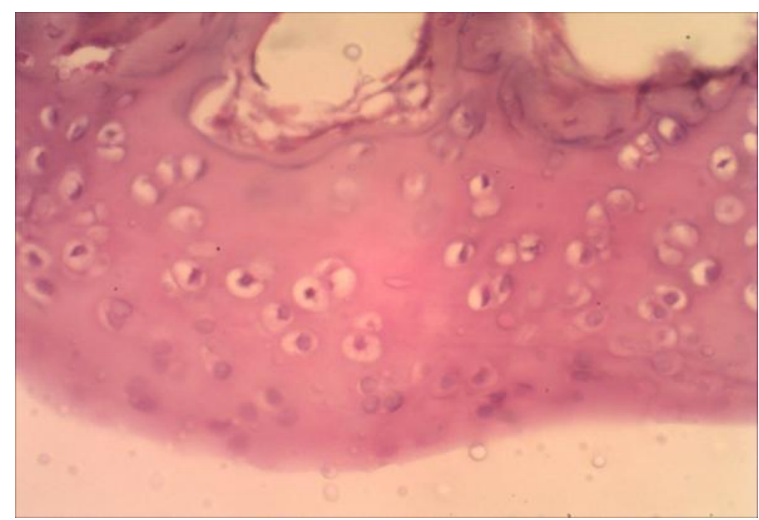

Figure 2: Right hind paw joint of normal control group. Normal joint space and cartilage with no inflammatory infiltrate. The arrows show normal joint cartilage. $X 400$

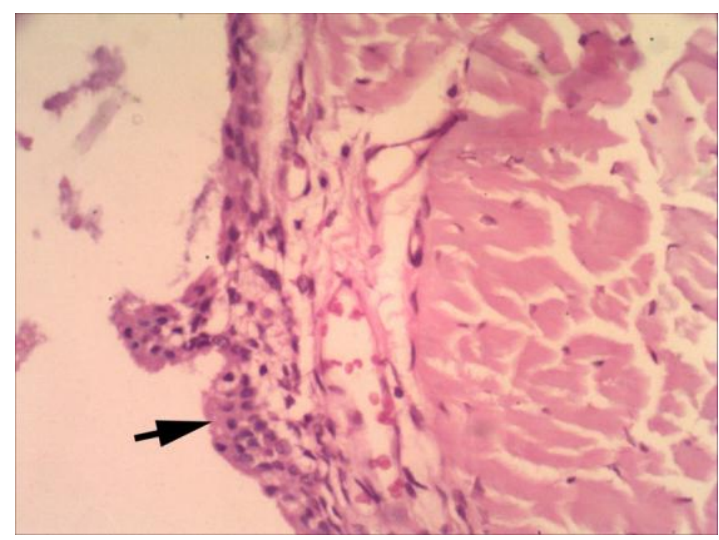

Figure 4: Right hind paw joint of atorvastatin group. $X 400$ arrow shows the fibrosis and inflammatory infiltrate

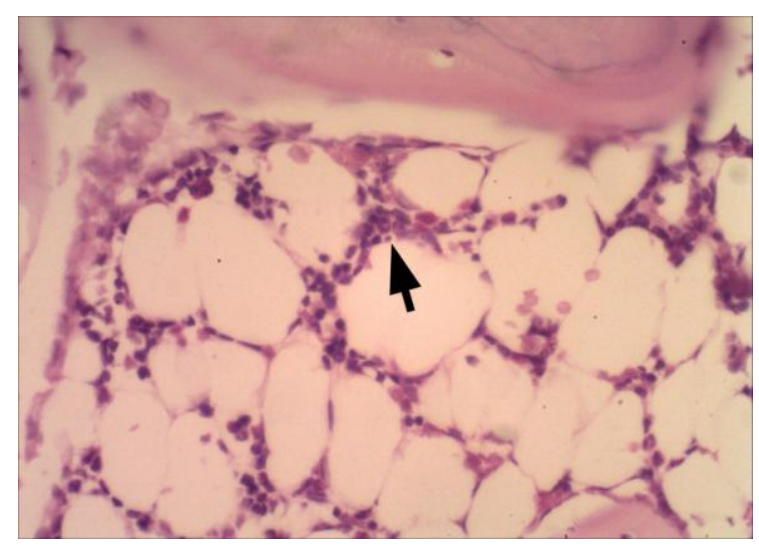

Figure 6: Right hind paw joint of atorvastatin plus MTX group (full dose). $X 400$ the arrow points to the inflammatory infiltrate. sustained functional and clinical outcomes in RA patients ${ }^{(14)}$.

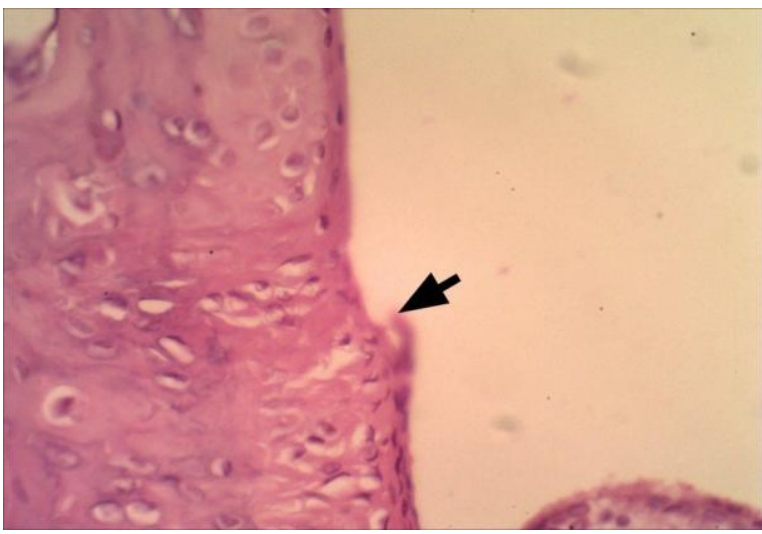

Figure 3: Right hind paw joint of arthritic control group. $X 400$ the arrow shows cartilage destruction

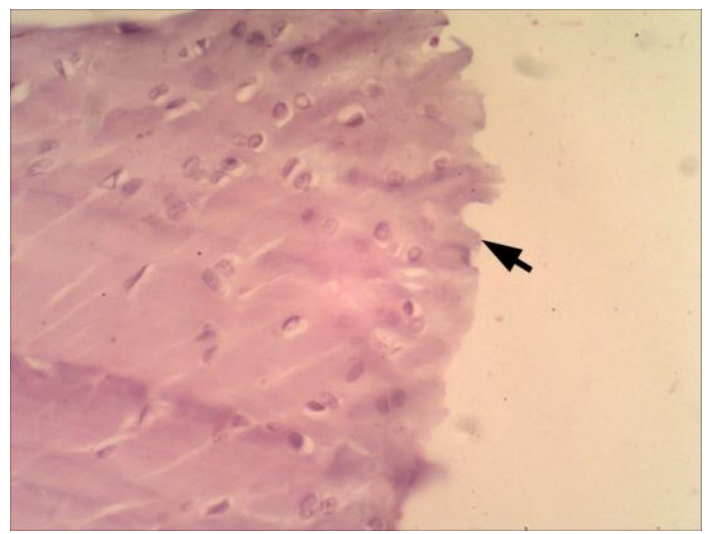

Figure 5: Right hind paw joint of methotrexate group. $\mathrm{X} 400$ showing cartilage destruction

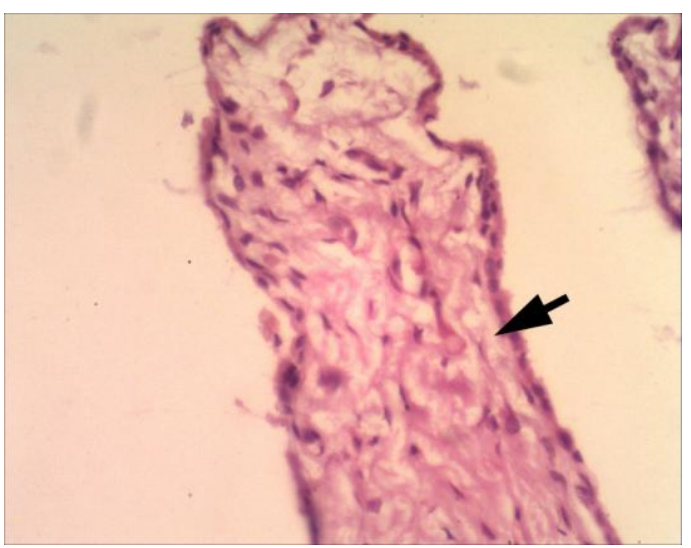

Figure 7: Right hind paw joint of atorvastatin plus MTX group (half dose) X 400 the arrow points to fibrosis. 


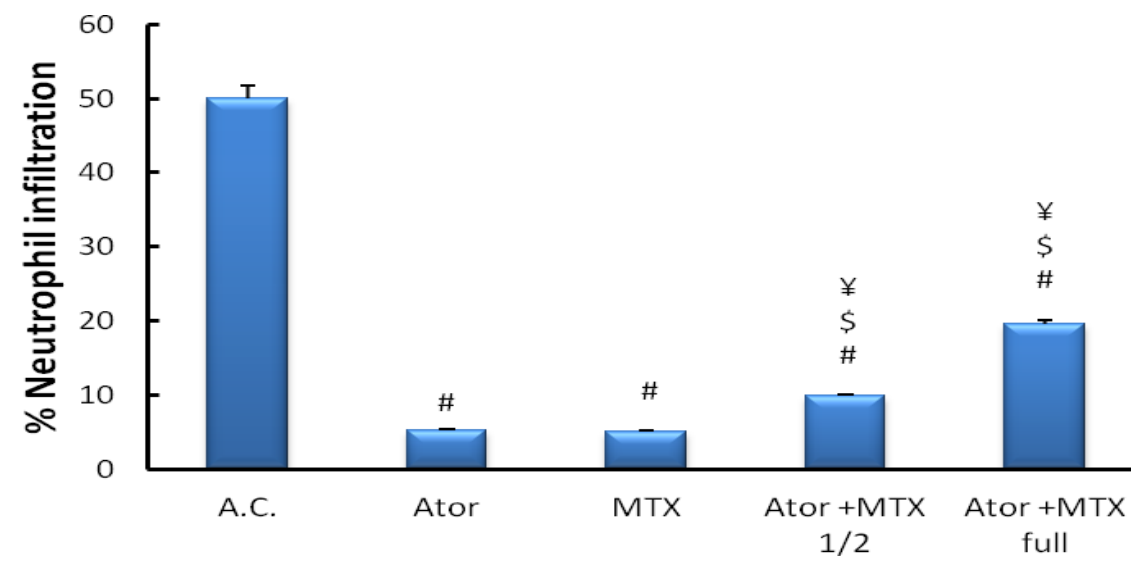

Fig. 8: Percent of neutrophil infiltration in the experimental groups. Monotherapy with atorvastatin or methotrexate or their combination significantly ameliorated the percent of neutrophil infiltration in arthritic rats. AC: arthritic control, Ator: atorvastatin, MTX: methotrexate. Results were expressed as mean \pm SEM and analyzed using one-way ANOVA followed by Bonferroni's test. ${ }^{\#} P<0.05$ vs. AC group, ${ }^{\$} P<0.05$ vs. atorvastatin group, ${ }^{*} P<0.05$ vs. MTX group. $n=6$.

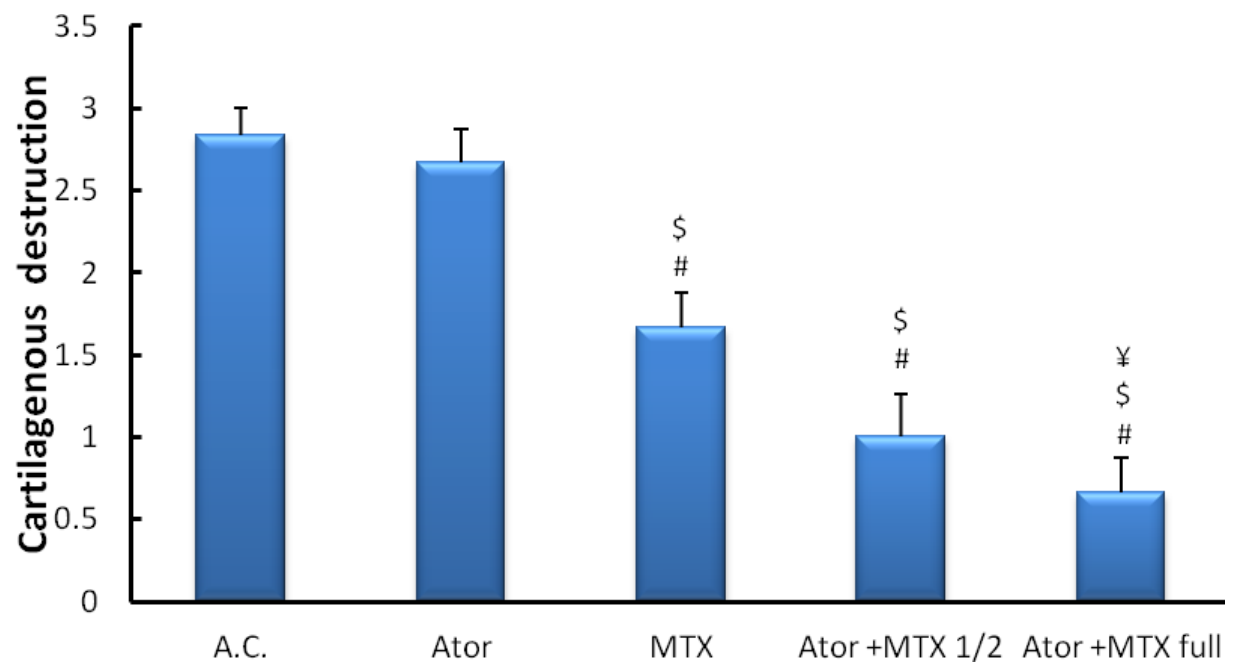

Figue 9: Score of cartilage destruction in the experimental groups. Monotherapy with methotrexate or its combination with atorvastatin significantly ameliorated the score of cartilage destruction in arthritic rats; also combination therapy in full dose significantly decreased this score as compared to monotherapy with methotrexate. AC: arthritic control, Ator: atorvastatin, MTX: methotrexate. Results were expressed as mean \pm SEM and analyzed using one-way ANOVA followed by Bonferroni's test. ${ }^{\#} P<0.05$ vs. AC group, ${ }^{\$} p<$ 0.05 vs. atorvastatin group, ${ }^{*} P<0.05$ vs. MTX group. $n=6$.

Since RA patients are more susceptible to cardiovascular diseases which is the most common cause of mortality in RA patients ${ }^{(15)}$; an increasing interest has aroused to study the effects of statins in improving RA. Adjuvant-induced arthritis in rats is a well established experimental model that has features similar to the human RA. It is characterized by chronic proliferative and inflammatory reactions in synovial membranes, producing pain, disability and eventually destruction of joints ${ }^{(16)}$. TNF- $\alpha$, a potent cytokine with diverse effects on multiple cell types, is produced by monocytes, 
macrophages, lymphocytes, and other cells. TNF- $\alpha$ is known to stimulate migration of lymphocytes to inflammatory sites such as the inflamed joint ${ }^{(17)}$. The antiinflammatory effects of MTX in the current study were supported by many previous studies. Hildner et al. showed that MTX suppresses the production of both TNF and IFN- $\gamma$ by $\mathrm{T}$-cell-receptor-primed $\mathrm{T}$ lymphocytes from both healthy human donors and RA patients ${ }^{(18)}$. Braun and Rau stated that MTX seems to even prolong the life span of patients who tolerate the drug and have clinical benefit from this therapy ${ }^{(19)}$. The use of MTX has been limited by some of its toxic manifestations, such as abdominal discomfort, alopecia, oral ulcerations, and cytopenia $^{(20)}$. Therefore, studies were made to use it in combination regimen- like the present study -to reduce the dose and for better effect. This agrees with many previous experiments. Bauerova et al. investigated the use of substances with antioxidant effects (coenzyme Q10 (CoQ10), carnosine, stobadinedipalmitate and pinosylvin) combined to MTX. All combinations tested showed a higher efficacy in affecting biochemical or immunological parameters than MTX administered in monotherapy ${ }^{(21)}$. The anti-inflammatory effects of statins in the current study was supported in several previous studies ${ }^{(22,23)}$. Also, statins modify apoptosis in smooth muscle, endothelial cells and synovial cells ${ }^{(24)}$ and bones $^{(25)}$, for instance, statins may have preserving effects on periarticular bone in RA joints. Their beneficial role in murine collagen-induced arthritis ${ }^{(26)}$, and refractory rheumatic disease was also proved ${ }^{(27)}$. The first placebo controlled study was conducted by McCarry et al. to investigate therapeutic effects and vascular risk factor modification of statins in RA patients. It showed a significant reduction in the disease activity score in atorvastatin group compared to placebo group in patients with $\mathrm{RA}^{(28)}$. Our current study was in agreement with many previous human studies that showed that patients with RA taking statins; had lower CRP and lower swollen joint counts compared to patients not taking statins ${ }^{(29)}$. Our findings were not well-matched with other studies that detected inflammatory marker in RA patient before and after $20 \mathrm{mg}$ atorvastatin therapy, while Lipid profile and arterial stiffness improved significantly ${ }^{(30)}$. Similar observation was made by Charles-Schoeman et al. with $80 \mathrm{mg}$ atorvastatin in double blind placebo control trial. The changes in measures of clinical activity were not significant but there was a trend for a decrease in CRP during2 weeks of treatment with statin $^{(31)}$. RA is still associated with an increased mortality mainly due to an increase in cardiovascular risk. Use of NSAIDs and glucocorticoids might be associated with an increased risk. The European League Against Rheumatism (EULAR) recommendations for cardio-vascular risk management in patients with rheumatoid arthritis and other forms of inflammatory arthritis are based on national guidelines regarding control of traditional cardiovascular risk factors $^{(32)}$. Hence, the benefit of use of statins and its combination with MTX will allow for reduction of its dose and reduced side effects.

\section{Conclusion}

The study concludes that Statins are very benifecial for patients of RA especially if combined with DMARD.

\section{References}

1. Mount C, Featherstone J.Rheumatoid arthritis market. Nat Rev Drug Discov. 2005: 4 (1):11-12.

2. Richard NM, Cotran RS. Acute and chronic inflammation. Robbins basic pathology $7^{\text {th }}$ ed. 2005; 2:33-50. 
3. Farnier M, Davignon J. Current and future treatment of hyperlipidemia: the role of statins. Am J Cardiol. 1998:82(4B):3-10.

4. Palinski W, Napoli C. Unraveling pleiotropic effects of statins on plaque rupture. Arterioscler Thromb Vasc Biol. 2002:22(11):1745-1750.

5. Grip O, Janciauskiene S, Lindgren S. Atorvastatin activates PPAR-gamma and attenuates the inflammatory response in human monocytes. Inflamm Res. 2002:51(2):58-62.

6. Schroder O, Stein J. Low dose methotrexate in inflammatory bowel disease: current status and future directions. Am J Gastroenterol. 2003: 98 (3):530-537.

7. Hasko G, Cronstein BN. Adenosine: an endogenous regulator of innate immunity. Trends Immunol. 2004: 25(1):33-39.

8. Dale J, Alcorn N, Capell H, Madhok R. (2007): Combination therapy for rheumatoid arthritis, methotrexate and sulfasalazine together or with other DMARDs. Nat Clin Pract Rheumatol. 3:450-458.

9. Barsante MM, Roffe E, Yokoro CM, Tafuri WL, Souza DG, Pinho V, Castro MS, Teixeira MM. Anti-inflammatory and analgesic effects of atorvastatin in a rat model of adjuvant -induced arthritis. Eur J Pharmacol. 2005: 516(3):282-289.

10. Rovenský J, Stančíková M, Švík K, Utěšený J, Bauerová K, Jurčovičová J. Treatment of adjuvant-induced arthritis with the combination of methotrexate and probiotic bacteria Escherichia coli 083 (Colinfant). Folia Microbiol (Praha).2009: 54(4): 359-363.

11. Bendele A, McComb J, Gould T, McAbee T, Sennello G, Chlipala E, Chlipala E, Guy M. Animal models of arthritis relevance to human disease. Toxicol Pathol. 1999:27 (1):134-142.

12. Joosten LA, Helsen MM Saxne T, van De Loo FA, Heinegard D, van Den Berg WB. IL-1 alpha beta blockade prevents cartilage and bone destruction in murine type II collagen-induced arthritis, whereas TNF-alpha blockade only ameliorates joint inflammation. J Immunol. 1999: 163 (9):5049-5055.

13. Mitchell KL, Pisetsky DS. Early rheumatoid arthritis. Curr Opin Rheumatol. 2007:19(3):278-283.

14. Sizova L. Approaches to the treatment of early rheumatoid arthritis with diseasemodifying antirheumatic drugs. Br J Clin Pharmacol. 2008:66 (2):173-178.

15. Kitas GD, Gabriel SE. Cardiovascular disease in rheumatoid arthritis: state of the art and future perspectives. .Ann Rheum Dis. 2011:70(1):8-14.

16. Francischi JN, Yokoro CM, Poole S, Tafuri WL, Cunha FQ, Teixeira MM. Antiinflammatory and analgesic effects of the phosphodiesterase 4 inhibitor rolipram in a rat model of arthritis. Eur $\mathrm{J}$ Pharmacol. 2000: 399 (2-3):243-249.

17. Keystone EC. B cells in rheumatoid arthritis: from hypothesis to the clinic. Rheumatology (Oxford). 2005: 44(suppl 2):812.

18. Hildner K, Finotto S, Becker C, Schlaak J, Schirmacher P, Galle PR, MärkerHermann E, Neurath MF. Tumour necrosis factor [TNF] production by $\mathrm{T}$ cell receptor-primed $\mathrm{T}$ lymphocytes is a target for low dose methotrexate in rheumatoid arthritis. Clin Exp Immunol. 1999:118 (1):137-146.

19. Braun J, Rau R. An update on methotrexate. Curr Opin Rheumatol. 2009: 21 (3):216-223.

20. Alarcon GS, Tracy IC, Blackburn WD Jr. Methotrexate in rheumatoid arthritis: toxic effects as the major factor in limiting long term treatment. Arthritis Rheum. 1989:32(6): 671-676.

21. Bauerova K, Ponist S, Mihalova D, Drafi F, Kuncirova V. Utilization of adjuvant arthritis model for evaluation of new approaches in rheumatoid arthritis therapy focused on regulation of immune processes and oxidative stress. Interdisc Toxicol. 2011:4(1): 33-39.

22. Oliver AM, Clair EW. (2008): Rheumatoid arthritis Treatment Assessment. In: Klippel JH, Stone JH, Crofford L.J, White 
PH. (Eds) Primer on rheumatic diseases. $13^{\text {rd }}$ ed, Springer; 140.

23. Greenwood J, Steinman L, Zamvil SS. Statin therapy and autoimmune disease: from protein prenylation to immunomodulation. Nat Rev Immunol. 2006:6 (5):358-370.

24. Nagashima T, Okazaki H, Yudoh K, Matsuno H, Minota S. Apoptosis of rheumatoid synovial cells by statins through the blocking of protein geranylgeranylation: a potential therapeutic approach to rheumatoid arthritis. Arthritis Rheum. 2006: 54 (2):579-586.

25. Davignon J, Leiter LA. Ongoing clinical trials of the pleiotropic effects of statins. Vasc Health Risk Manag. 2005 1(1):29-40.

26. Palmer G, Chobaz V, Talabot-Ayer D, Taylor S, So A, Gabay C, Busso N. Assessment of the efficacy of different statins in murine collagen-induced arthritis. Arthritis Rheum. 2004:50 (12):4051-4059.

27. Abud-Mendoza C, De la Fuente H, Cuevas-Orta E, Baranda L, Cruz-Rizo J, Gonzalez-Amaro R. Therapy with statins in patients with refractory rheumatic diseases: a preliminary study. Lupus. 2003: 12(8):607-611.

28. McCarey DW, Mclnnes IB, Madhok R, Hampson R, Scherbakov O, Ford I, Capell $\mathrm{HA}$, Sattar N. Trial of atorvastatin in rheumatoid arthritis (TARA): doubleblind, randomized placebo-controlled trial. Lancet. 2004: 363(9426):2015-2121.

29. Okamoto H, Koizumi K, Kamitsuji S, Inoue E, Hara M, Tomatsu T, Kamatani N, Yamanaka $\mathrm{H}$. Beneficial action of statins in patients with rheumatoid arthritis in a large observational cohort. J Rheumatol. 2007:34 (5):964-968.

30. Van Doornum S, McColl G, Wicks IP. Atorvastatin reduces arterial stiffness in patients with rheumatoid arthritis. Ann Rheum Dis. 2004: 63 (12):1571-1575.

31. Charles-Schoeman C, Khanna D, Furst DE, McMahon M, Reddy ST, Fogelman AM, Paulus HE, Park GS,Gong T, Ansell BJ.Effects of high dose atorvastatin on anti inflammatory properties of high density lipoprotein in patients with rheumatoid arthritis. J Rheumatol. 2007: 34(7):1459-1464.

32. Kleinert S, Krueger K. Cardiovascular comorbidity and its risk factors in rheumatoid arthritis. Z Rheumatol. 2011; 70 (6):464-472. 
